\title{
IL-32 exacerbates adenoid hypertrophy via activating NLRP3- mediated cell pyroptosis, which promotes inflammation
}

\author{
JUNMEI ZHANG, XUYUAN SUN, LINGLING ZHONG and BEI SHEN \\ Department of Otolaryngology, Tianjin Children's Hospital, Tianjin 300134, P.R. China
}

Received October 20, 2020; Accepted January 11, 2021

DOI: $10.3892 / \mathrm{mmr} .2021 .11865$

\begin{abstract}
Adenoid hypertrophy (AH) is a common pediatric disease caused by inflammatory stimulation. The pro-inflammatory cytokine IL-32 has been reported to promote airway inflammation and also be involved in the pyroptosis pathway. However, whether IL-32 can contribute to AH by mediating pyroptosis remains to be elucidated. The present study aimed to investigate the role of IL-32 in $\mathrm{AH}$ and determine the potential underlying mechanisms. Adenoid tissues were collected from healthy children and children with AH, and the expression of IL-32, NACHT LRR and PYD domains-containing protein 3 (NLRP3) and IL-1 $\beta$ in normal and hypertrophic tissues were measured. Human nasal epithelial cells (HNEpCs) were exposed to a series of IL-32 concentrations. HNEpCs with or without IL-32 silencing were stimulated with lipopolysaccharide (LPS), and cell proliferation, cell apoptosis, gasdermin D (GSDMD) activation, production of inflammatory cytokines and the expression levels of proteins related to the potential mechanisms were evaluated by Cell Counting Kit-8, flow cytometry, immunofluorescence staining, ELISA and western blot assays, respectively. The results showed that IL-32, NLRP3 and IL-1 $\beta$ exhibited higher expression in adenoid tissues with $\mathrm{AH}$ compared with normal tissues. In HNEpC cells, treatment with IL-32 (2 and $10 \mathrm{ng} / \mathrm{ml}$ ) promoted cell proliferation, while $50 \mathrm{ng} / \mathrm{ml} \mathrm{IL-32}$ inhibited cell proliferation at 12, 24 and $48 \mathrm{~h}$ post-treatment. IL-32 (2, 10 and $50 \mathrm{ng} / \mathrm{ml})$ also resulted in differing degrees of apoptosis, GSDMD activation, release of IL-1 $\beta$, IL- 6 and TNF- $\alpha$, and increased protein expression levels of NLRP3, cleaved-caspase-1, activated GSDMD, nucleotide-binding oligomerization domain-containing protein (NOD) 1/2 and Toll-like receptor (TLR) 4 in a concentration-dependent manner. In addition, compared with the LPS group, IL-32 knockdown significantly inhibited LPS-induced enhancement of cell proliferation, cell apoptosis, GSDMD activation
\end{abstract}

Correspondence to: Dr Junmei Zhang, Department of Otolaryngology, Tianjin Children's Hospital, 238 Longyan Road, Beichen, Tianjin 300134, P.R. China

E-mail: zhangjunmeiii@sina.com

Key words: adenoid, IL-32, inflammation, pyroptosis and production of inflammatory cytokines, and reversed the increased protein expression of NLRP3, cleaved-caspase-1, activated GSDMD, NOD1/2 and TLR4. In conclusion, IL-32 may play a role in the progression of $\mathrm{AH}$ via promoting inflammation, and the potential mechanism may involve the activation of NLRP3-mediated pyroptosis.

\section{Introduction}

Adenoids are lymphatic tissues of the nasopharynx located at the junction of the posterior wall of the nasopharynx and between the pharyngeal recesses on both sides. Adenoids exist from birth, and can gradually shrink after 8-10 years of age under normal physiological conditions (1). Adenoid hypertrophy $(\mathrm{AH})$ is caused when the adenoid is stimulated by repeated inflammation, thus resulting in its pathological hypertrophy (2). AH is a common pediatric disease that may cause a series of local and systemic symptoms, such as nasal congestion, snoring, mouth breathing and obstructive sleep apnea. These symptoms may lead to hypoxia and carbon dioxide retention, thereby affecting children's intellectual development (3). AH can also directly cause mandibular dysplasia, leading to an adenoid facial appearance (4).

The main cause of $\mathrm{AH}$ is mainly bacterial virus infection, but there are also other factors, such as allergen stimulation. $\mathrm{AH}$ is the hypertrophy of lymphoid tissue (loose connective tissue) and lymphatic follicles, or may also be hypertrophy of mucosal epithelial cells (5). The hypertrophy process is also accompanied by increased numbers of various lymphocytes, which further aggravates the stimulation. The inflammatory stimulation of epithelial cells on the surface of adenoids can directly or indirectly cause rhinitis and sinusitis (6). Inflammatory products that invade the eustachian tube on both sides can cause otitis media (7). However, the related underlying mechanisms of adenoid epithelial cell hypertrophy have not been fully elucidated.

IL-32 is a pro-inflammatory cytokine produced by $\mathrm{T}$ lymphocytes, natural killer cells, monocytes and epithelial cells, and its association with airway inflammation has demonstrated in a number of studies (8). For example, IL-32 was identified as an important cytokine involved in the inflammation of allergic rhinitis (AR) (9). Inhibition of IL-32 signaling was shown to attenuate AR in both cellular and animal models $(10,11)$. Elevated levels of IL-32 were also found to play a role in the pathogenesis of rhinosinusitis through its role as 
a pro-inflammatory cytokine (12). However, whether IL-32 is involved in $\mathrm{AH}$ remains to be elucidated.

IL-32 can exert its pro-inflammatory role via numerous pathways or mediators, including $\mathrm{p} 38, \mathrm{MAPK}, \mathrm{NF}-\kappa \mathrm{B}$, caspase-1 and caspase-3 (13). In fact, these pathways are interrelated. For example, IL-32 can activate the NF- $\kappa$ B pathway by increasing nucleotide-binding oligomerization domain-containing protein (NOD) 1 and NOD2 expression, therefore promoting NACHT LRR and PYD domains-containing protein 3 (NLRP3) activation and IL-1 $\beta$ production (14). Exogenous activation of NOD1 and NOD2 can also in turn promote the secretion of IL-32, stimulate the activation and release of IL-1 $\beta$ through the caspase-1 pathway and thus further mediate the progression of inflammation (15). Notably, NLRP3-mediated caspase-1 activation was recently confirmed to trigger cell pyroptosis, a form of programmed cell death (16). Moreover, the NLRP3 inflammasome was implicated to promote the development and progression of AR by enhancing inflammatory responses and epithelium pyroptosis (17).

The present study demonstrated IL-32 expression in the adenoid tissues of patients with AH. IL-32 stimulation significantly promoted the production of pro-inflammatory cytokines and cell pyroptosis in human nasal epithelial cells. Meanwhile, silencing of IL-32 significantly inhibited LPS-induced inflammation and pyroptosis.

\section{Materials and methods}

Sample collection. The study cohort in the present investigation consisted of 10 children (age range, 6-12 years; 4 female patients and 6 male patients) diagnosed with AH in Tianjin Children's Hospital (Tianjin, China) between February 2019 and June 2019. The diagnosis of AH was based on patient history as well as physical and endoscopic examinations. The normal group consisted of 10 healthy children without $\mathrm{AH}$, but needed required operation on the adenoid due to other reasons. Tissue was collected from the adenoid during surgical operation and immediately stored in liquid nitrogen before use. Parents of the children were informed about the study and signed consent was obtained. The study was approved by the Ethics Committee of Tianjin Children's Hospital (approval no. IACUC-20190111-13).

Cell culture and treatment. Human nasal epithelial cells (HNEpC; RPMI 2650, ATCC-CCL-30; https:/www.atcc. org/products/all/CCL-30.aspx), which exhibit epithelioid morphology and have been largely utilized in previous studies as the nasal epithelial cell (18-21), were purchased from American Type Culture Collection. Cells were cultured in DMEM (Invitrogen; Thermo Fisher Scientific, Inc.) supplemented with $10 \%$ fetal bovine serum (Gibco; Thermo Fisher Scientific, Inc.), $100 \mu \mathrm{g} / \mathrm{ml}$ streptomycin and $100 \mathrm{U} / \mathrm{ml}$ penicillin in an incubator at $37^{\circ} \mathrm{C}$.

Cells were cultured overnight to reach $80-90 \%$ confluence before transfection. IL-32 small interfering RNA (siRNA) (cat. no. sc-60841) and control siRNA-A (cat. no. sc-37007) were purchased from Santa Cruz Biotechnology, Inc. Transfection was performed using Lipofectamine ${ }^{\circledR} 2000$ transfection reagent (Invitrogen; Thermo Fisher Scientific, Inc.). All experiments were performed in strict accordance with the manufacturer's instructions. At $48 \mathrm{~h}$ post-transfection, the cells were selected for subsequent experiments.

Cell Counting Kit-8 (CCK-8) assay. The cell proliferation of HNEpCs exposed to different concentrations (0,2,10 and $50 \mathrm{ng} /$ $\mathrm{ml}$ ) of recombinant human IL-32 (R\&D Systems, Inc.) for 12, 24 and $48 \mathrm{~h}$ (22), as well as HNEpCs transfected with IL-32 siRNA or siRNA-negative control (NC) in the presence of lipopolysaccharide (LPS; $1 \mu \mathrm{g} / \mathrm{ml}$; Beijing Solarbio Science \& Technology Co., Ltd.) stimulation for 12, 24 and $48 \mathrm{~h}$, were determined using a CCK-8 assay (cat. no. HY-K0301; MedChemExpress), according to the manufacturer's instructions.

Hematoxylin and eosin $(H \& E)$ staining. Adenoid tissues were fixed with $10 \%$ formalin (Beyotime Institute of Biotechnology) at $4^{\circ} \mathrm{C}$ for $24 \mathrm{~h}$ and embedded in paraffin following alcohol dehydration. The tissues were sliced at a thickness of $4 \mathrm{~mm}$ according to the manufacturer's protocol (Leica Autostainer XL; Leica Microsystems, Inc.) and stained with H\&E at room temperature for 2 min (Thermo Fisher Scientific, Inc.). Stained samples were observed under light microscopy (magnification, x200; Olympus FV-1mm; Olympus Corporation).

Immunohistochemical staining. For immunohistochemical analysis, the tissue slides were dewaxed in xylene, rehydrated using graded ethanol, and then heated to expose antigenic sites. Following antigenic retrieval, the sections were incubated overnight at $4{ }^{\circ} \mathrm{C}$ with diluted rabbit polyclonal antibody against IL-32 (cat. no. ab37158; Abcam; 1:1,000) at a concentration of $10 \mu \mathrm{g} / \mathrm{ml}$. An HRP-conjugated anti-rabbit secondary antibody (cat. no. ab6721; Abcam; 1:1,000) were used and detected with peroxidase-labelled streptavidin, both incubated for $10 \mathrm{~min}$ at room temperature. Immunoreactivity was visualized by incubating the sections for $2 \mathrm{~min}$ in $0.1 \%$ 3,3'-diaminobenzidine (Beyotime Institute of Biotechnology). The sections were observed under a light microscope (Carl Zeiss AG) and photographed with a digital camera (AxioCam MRc5; Zeiss AG). IL-32 expression is shown by a brown or dark brown stain, while blue staining indicates negative expression. The darker the brown color, the higher the expression of IL-32.

Flow cytometry. Cell apoptosis was measured using flow cytometry analysis based on an Annexin V-FITC Apoptosis Detection kit (Sigma-Aldrich; Merck KGaA) according to the manufacturer's protocol. In brief, HNEpCs and cells transfected with siRNA-IL-32 were seeded at a density of $1 \times 10^{5}$ cells/well in a six-well culture plate and treated with IL-32 or LPS. The cells were then harvested with $0.25 \%$ trypsin, washed twice with cold PBS and suspended in $500 \mu \mathrm{l}$ binding buffer that was included in the kit. The cells were then incubated with $500 \mu 1$ Annexin $\mathrm{V}$ and $500 \mu \mathrm{l}$ propidium iodide reagent in the dark for $20 \mathrm{~min}$. Analysis was performed using a BD FACSAria flow cytometer (Becton, Dickinson and Company) and iSort Automated Cell Sorter software (version A.0; Thermo Fisher Scientific, Inc.).

Immunofluorescence (IF) staining. The expression of cleaved gasdermin D (GSDMD) was detected by IF staining. In brief, cells were exposed to $4 \%$ paraformaldehyde for $20 \mathrm{~min}$ and then blocked with 1\% BSA (Gibco; Thermo Fisher 
Scientific, Inc.) and $0.1 \%$ Triton- $\mathrm{X}$ for $2 \mathrm{~h}$ at room temperature. Subsequently, the cells were incubated with primary antibody against the N-terminal of GSDMD (GSDMD-N; cat. no. ab215203; 1:1,000; Abcam) at $4^{\circ} \mathrm{C}$ overnight, followed by incubation with goat anti-rabbit IgG-H\&L secondary antibody (cat. no. ab150077; 1:500; Abcam) for $2 \mathrm{~h}$ at room temperature. The nuclei were stained with DAPI (Beyotime Institute of Biotechnology) at room temperature for $5 \mathrm{~min}$. Stained cells were observed using a fluorescence microscope.

ELISA. ELISA kits were used to measure the concentrations of IL-1 $\beta$ (cat. no. ab217608; Abcam), IL-6 (cat. no. ab46027; Abcam) and TNF- $\alpha$ (cat. no. ab181421; Abcam) as per the manufacturer's instructions. Briefly, $50 \mu \mathrm{l}$ samples or standards were added to appropriate wells. This was followed by the addition of antibody cocktails from the ELISA kits into each well and incubation at room temperature for $1 \mathrm{~h}$. Subsequently, 3,3',5,5'-tetramethylbenzidine substrate from the kits was added to each well and incubated for $10 \mathrm{~min}$ in the dark with shaking at $400 \mathrm{rpm}$. Following incubation with stop solution, the optical density values of each well were measured at a wavelength of $450 \mathrm{~nm}$ using a microplate reader.

Reverse transcription-quantitative PCR (RT-qPCR). Total RNA was extracted from HNEpCs using TRIzol ${ }^{\circledR}$ reagent (Invitrogen; Thermo Fisher Scientific, Inc.). RT to synthesize cDNA was performed using SuperScript ${ }^{\mathrm{TM}}$ III Reverse Transcriptase (Thermo Fisher Scientific, Inc.) according to the manufacturer's protocol. The PCR reaction system was prepared using SYBR ${ }^{\circledR}$ Green Real-Time PCR Master mix (Thermo Fisher Scientific, Inc). The following primers for IL-32 were used: Forward, 5'-GGCTGAGTATTTGTGCCAGG-3' and reverse, 5'-TATGGCCTGGTGCATTCGG-3'. The following thermocycling conditions were used for qPCR: $95^{\circ} \mathrm{C}$ for $2 \mathrm{~min}$, followed by 40 cycles of $95^{\circ} \mathrm{C}$ for $20 \mathrm{sec}$ and $65^{\circ} \mathrm{C}$ for $40 \mathrm{sec}$. The expression levels of IL-32 were normalized to the endogenous control GAPDH (forward, 5'-AATGGGCAGCCGTTAGGAAA-3' and reverse, 5'-AATGGGCAGCCGTTAGGAAA-3') using the $2^{-\Delta \Delta C q}$ method (23).

Western blotting. Total protein was extracted from adenoid tissues and HNEpC cells using RIPA lysis buffer (Beyotime Institute of Biotechnology). Following mixing with SDS lysis buffer and boiling, the protein content in cell lysates were measured using BCA Protein Assay reagent (Pierce; Thermo Fisher Scientific, Inc.). Equal amounts of protein $(30 \mu \mathrm{g})$ were loaded onto $12 \%$ SDS-PAGE and separated via electrophoresis, then separated proteins were transferred to PVDF membranes. Following blocking in 5\% skimmed milk at room temperature for $2 \mathrm{~h}$, membranes were incubated overnight with primary antibodies against IL-32 (cat. no. ab37158; 1:1,000; Abcam), NLRP3 (cat. no. ab263899; 1:1,000; Abcam), IL-1 $\beta$ (cat. no. ab216995; 1:1,000; Abcam), caspase-1 (cat. no. ab207802; 1:1,000; Abcam), GSDMD-N (cat. no. ab215203; 1:1,000; Abcam), NOD1 (cat. no. ab189435; 1:1,000; Abcam), NOD2 (cat. no. ab31488; 1:500; Abcam), Toll-like receptor 4 (TLR4; cat. no. ab13556; 1:500; Abcam) and GAPDH (cat. no. ab8245; 1:5,000; Abcam). Membranes were then incubated with goat anti-rabbit IgG (cat. no. ab6721; Abcam; 1:2,000) or goat anti-mouse IgG (cat. no. ab6789; Abcam; 1:2,000) secondary antibodies at room temperature for $2 \mathrm{~h}$. Proteins were then visualized using a gel imaging system (Amersham; Cytiva). Protein expression levels were semi-quantified using Image-Pro Plus software (version 6.0; Media Cybernetics, Inc.).

Statistical analysis. All generated data were analyzed using SPSS software (version 22.0; IBM Corp.). All experiments were repeated at least three times. Data are presented as the mean $\pm \mathrm{SD}$. An unpaired Student's t-test was conducted for two-group comparisons. One-way ANOVA followed by Tukey's post hoc test was performed to compare between three or more groups. $\mathrm{P}<0.05$ was considered to indicate a statistically significant difference.

\section{Results}

IL-32 is upregulated in adenoid tissues with AH. Firstly, to determine whether IL-32 is involved in AH, IL-32 expression in normal and hypertrophic adenoid tissues was detected. Fig. 1A demonstrates the typical pathological manifestation of hypertrophy and hyperplasia in adenoid tissues from patients with $\mathrm{AH}$. Compared with the normal group, the obvious hypertrophy and lymphocyte infiltration can be observed in the adenoid epithelial tissue of the hyperplasia group. Immunohistochemical analysis (Fig. 1B) revealed that IL-32 expression was markedly upregulated in hypertrophic adenoid tissues compared with normal tissues. Consistently, western blot analysis confirmed higher protein expression of IL-32 in hypertrophic adenoid tissues (Fig. 1C). Meanwhile, the protein expression levels of NLRP3 and IL-1 $\beta$, which both play important roles in inflammation and pyroptosis, were also significantly increased in hypertrophic adenoid tissues (Fig. 1C). These data indicated that IL-32, together with inflammation and pyroptosis, may contribute to $\mathrm{AH}$ progression.

IL-32 induces apoptosis and inflammation. Subsequently, HNEpCs were utilized as the cell model and exposed to different concentrations $(0,2,10$ and $50 \mathrm{ng} / \mathrm{ml})$ of recombinant human IL-32. Fig. 2A shows the cell proliferation rate at 12, 24 and $48 \mathrm{~h}$ post IL-32 treatment, revealing that $2 \mathrm{ng} / \mathrm{ml}$ IL-32 promoted cell proliferation at $48 \mathrm{~h}$ post-treatment, while $10 \mathrm{ng} / \mathrm{ml} \mathrm{IL-32}$ significantly promoted cell proliferation at 24 and $48 \mathrm{~h}$ posttreatment, owing to the stressful cell proliferation caused by mild inflammation upon IL-1 $\beta$ activation (24). Meanwhile, $50 \mathrm{ng} / \mathrm{ml}$ IL-32 significantly inhibited cell proliferation, which can be explained by significant apoptosis or cell death (Fig. 2B and C) caused by $50 \mathrm{ng} / \mathrm{ml} \mathrm{IL-32} \mathrm{treatment.} \mathrm{In} \mathrm{the} \mathrm{following}$ experiments, cells were exposed to 2,10 and $50 \mathrm{ng} / \mathrm{ml}$ for $48 \mathrm{~h}$. The results shown in Fig. $2 \mathrm{~B}$ and $\mathrm{C}$ revealed that $10 \mathrm{ng} / \mathrm{ml} \mathrm{IL}-32$ significantly increased the ratio of cell apoptosis, and $50 \mathrm{ng} / \mathrm{ml}$ IL-32 resulted in an especially high ratio of apoptosis (nearly 6-fold of the control). As shown in Fig. 2D, IL-32 also increased the production of pro-inflammatory cytokines, including TNF- $\alpha$, IL- 6 and IL-1 $\beta$, in a concentration-dependent manner. These results suggested that IL-32 could induce apoptosis and inflammation in normal HNEpCs.

IL-32 promotes NLRP3-mediated pyroptosis. Subsequently, the present study assessed whether IL-32 could induce pyroptosis 
A

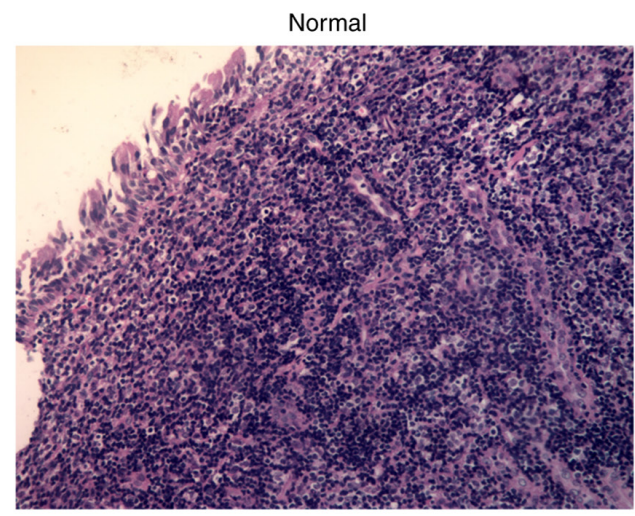

B

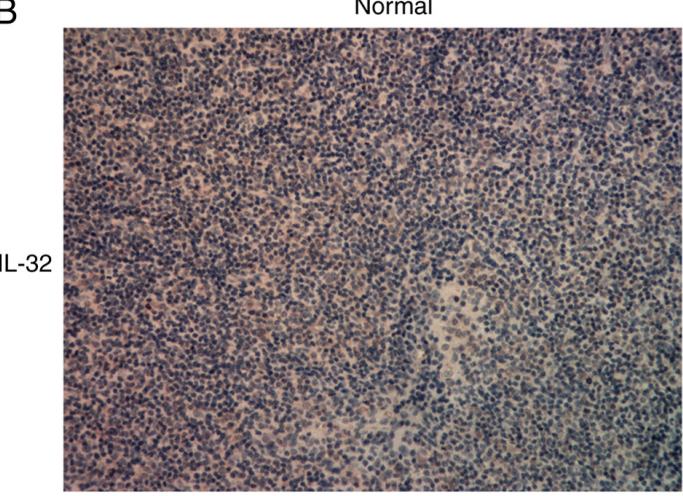

C
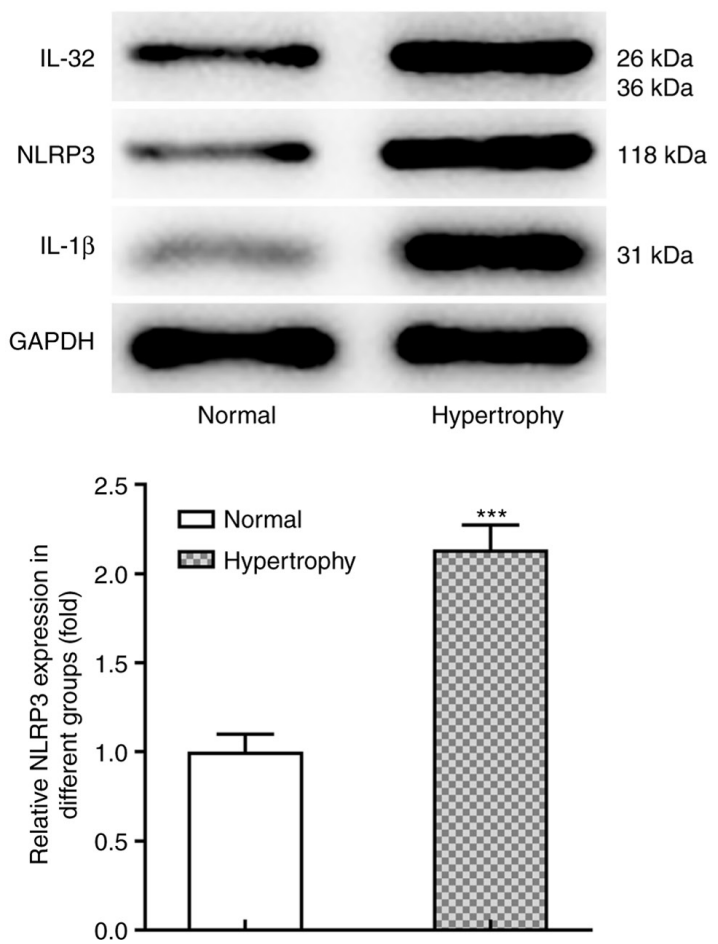

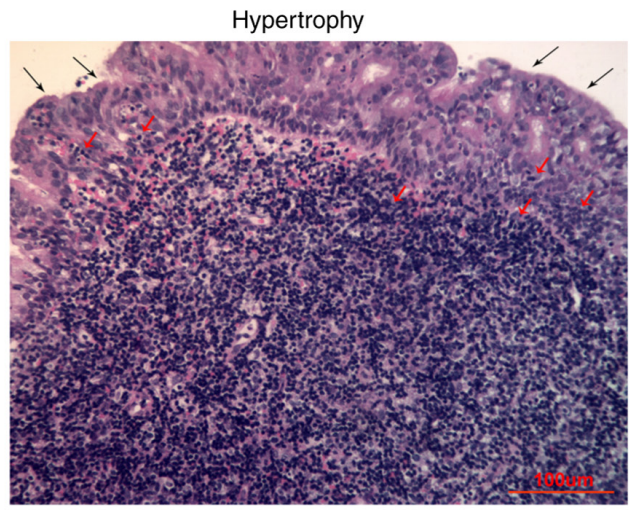

Hypertrophy
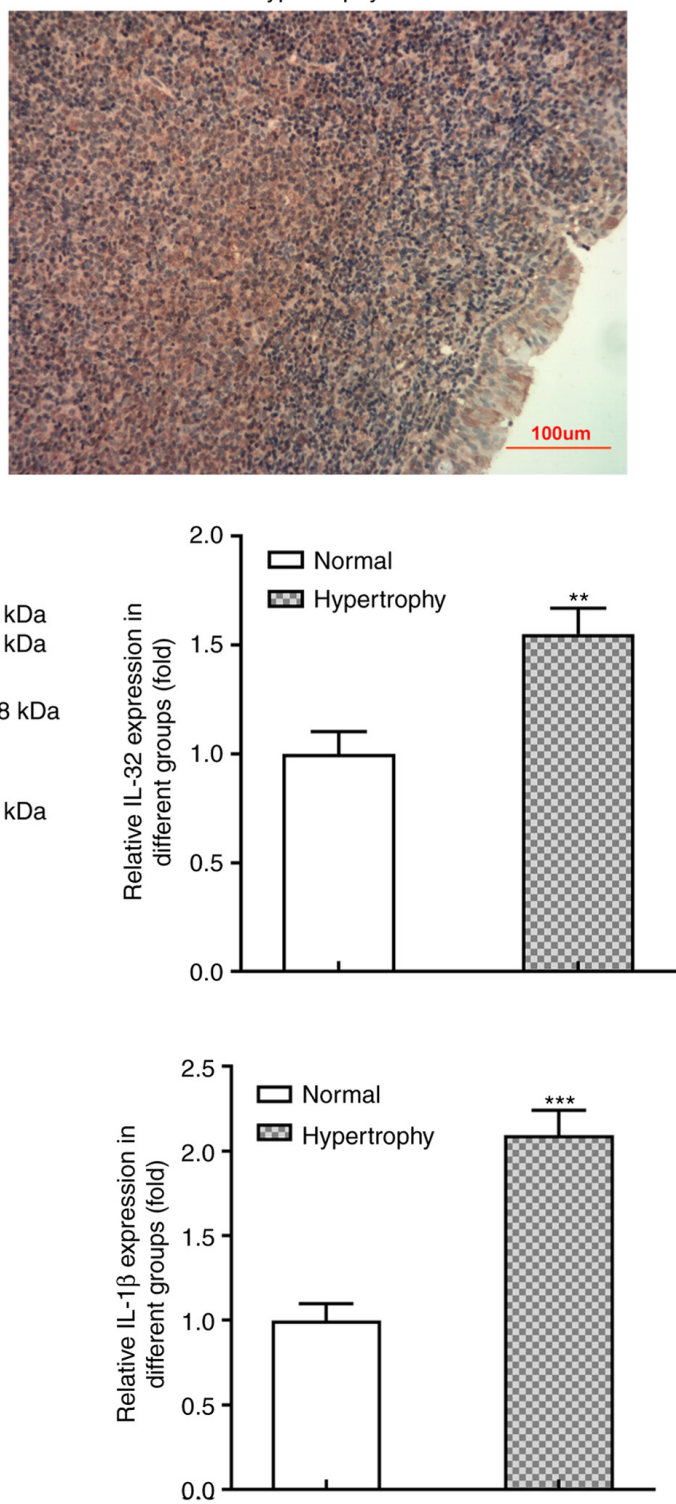

Figure 1. IL-32 is upregulated in AH tissues. (A) Representative images of H\&E staining in adenoid tissues from healthy (normal) children and children with AH (hypertrophy). Black arrow indicates hypertrophic epithelial tissue; red arrow indicates lymphocyte infiltration. (B) Immunohistochemical analysis for IL-32 in adenoid tissues form healthy (normal) children and children with AH (hypertrophy). IL-32 is stained with brown or dark brown and blue represents negative staining. Scale bar, $100 \mu \mathrm{m}$. (C) Protein expression levels of IL-32, NLRP3 and IL-1 $\beta$ in normal and hypertrophic adenoid tissues were determined via western blotting $(\mathrm{n}=10) .{ }^{* *} \mathrm{P}<0.01$ and ${ }^{* * *} \mathrm{P}<0.001$ vs. Normal. AH, adenoid hypertrophy; NLRP3, NACHT LRR and PYD domains-containing protein 3.

in HNEpCs. IF staining (Fig. 3A) illustrated that IL-32 stimulation significantly enhanced the activation (cleavage) of GSDMD, suggesting the occurrence of pyroptosis. Similar results were observed in Fig. 3B, which show the protein expression of NLRP3, cleaved-caspase-1 and GSDMD-N in response to IL-32 stimulation. NLRP3, cleaved-caspase-1 and 

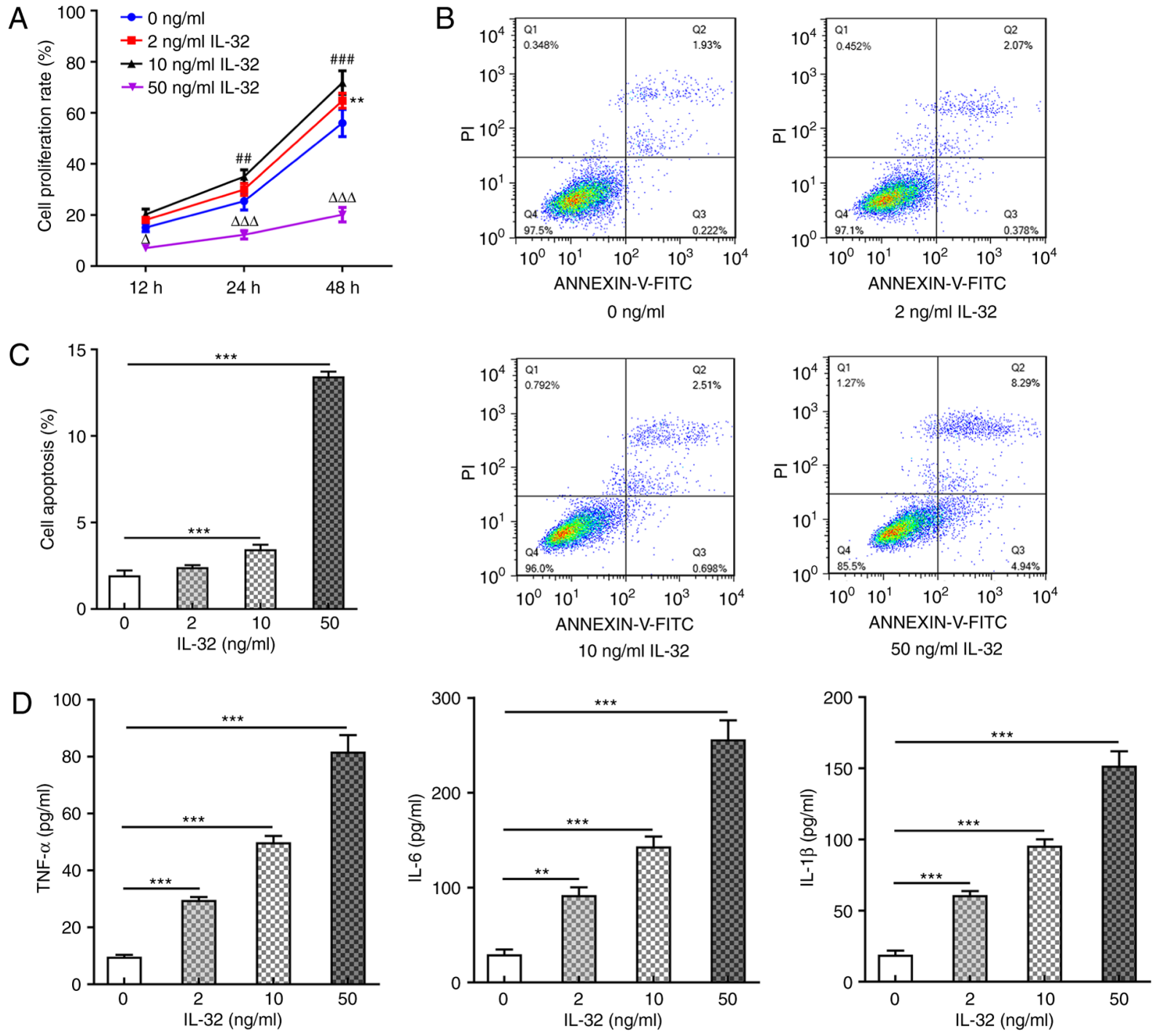

Figure 2. Effects of IL-32 on HNEpC proliferation, apoptosis and inflammation. (A) The cell proliferation rate of HNEpCs exposed to 0,2, $10 \mathrm{and} 50 \mathrm{ng} / \mathrm{ml}$ IL-32 for 12,24 and $48 \mathrm{~h} .{ }^{* *} \mathrm{P}<0.01,2$ vs. $0 \mathrm{ng} / \mathrm{ml} \mathrm{IL}-32 ;{ }^{\# \#} \mathrm{P}<0.01$ and ${ }^{\# \# \#} \mathrm{P}<0.001,10$ vs. $0 \mathrm{ng} / \mathrm{ml} \mathrm{IL}-32 ;{ }^{\Delta} \mathrm{P}<0.05$ and ${ }^{\Delta \Delta \Delta} \mathrm{P}<0.001,50 \mathrm{vs} .0 \mathrm{ng} / \mathrm{ml} \mathrm{IL}-32$. (B and C) The apoptosis ratio of HNEpCs exposed to $0,2,10$ and $50 \mathrm{ng} / \mathrm{ml} \mathrm{IL-32} \mathrm{for} 48 \mathrm{~h}$ was detected by flow cytometry. ${ }^{* * *} \mathrm{P}<0.001 \mathrm{vs} .0 \mathrm{ng} / \mathrm{ml} \mathrm{IL}-32$. (D) The concentration of TNF- $\alpha$, IL- 6 and IL-1 $\beta$ in the culture medium of HNEpCs exposed to $0,2,10$ and $50 \mathrm{ng} / \mathrm{ml}$ IL-32 for $48 \mathrm{~h}$ was detected via ELISA. .* P $<0.01$ and ${ }^{* * *} \mathrm{P}<0.001$, vs. $0 \mathrm{ng} / \mathrm{ml}$ IL-32. HNEpC, human nasal epithelial cells.

GSDMD-N expression levels were also markedly increased upon IL-32 stimulation. In addition, following exposure to 2, 10 and $50 \mathrm{ng} / \mathrm{ml} \mathrm{IL-32,} \mathrm{the} \mathrm{protein} \mathrm{expression} \mathrm{levels} \mathrm{of} \mathrm{NOD1,}$ NOD2 and TLR4 were also significantly enhanced (Fig. 3C). The aforementioned data indicated that IL-32 could induce pyroptosis of normal HNEpCs.

Knockdown of IL-32 inhibits LPS-induced inflammation and pyroptosis. Next, to further examine the modulatory role of IL-32 in AH, IL-32 expression levels in HNEpCs were knocked down using siRNAs. IL-32 siRNA-1 was chosen for subsequent experiments due to its enhanced silencing effects (Fig. 4A). LPS was used to stimulate control HNEpC cells and IL-32 knockdown cells. Similar to low concentrations of IL-32 (2 and $10 \mathrm{ng} / \mathrm{ml}$ ), LPS also significantly promoted cell proliferation compared with the control group (Fig. 4B). However, cells silenced with IL-32 siRNA-1 in the presence of LPS exerted a lower proliferation rate compared with cells transfected with NC vectors (Fig. 4B). LPS also enhanced the ratio of cell apoptosis, which was reversed by IL-32 knockdown (Fig. 4C and D). In addition, LPS resulted in the production of a large amount of pro-inflammatory cytokines, including IL-32, IL-1 $\beta$, IL-6 and TNF- $\alpha$, which was significantly inhibited by IL-32 silencing (Fig. 4E). These results revealed that silencing of IL-32 could inhibit LPS-induced acceleration of proliferation, apoptosis and inflammation.

Finally, the expression levels of proteins involved in NLRP3-mediated pyroptosis were evaluated. As shown in Fig. 5A, cells exerted significantly higher expression of cleaved GSDMD in response to LPS stimulation, while the knockdown of IL-32 markedly inhibited GSDMD activation. As presented in Fig. 5B, LPS also increased the expression of NLRP3, cleaved-caspase-1 and GSDMD-N, which was reversed by IL-32 silencing. As illustrated in Fig. 5C, the LPS-induced enhanced expression of NOD1, NOD2 and TLR4 was notably inhibited by IL-32 knockdown. These data indicated that IL-32 knockdown could effectively inhibit LPS-induced pyroptosis. 
A
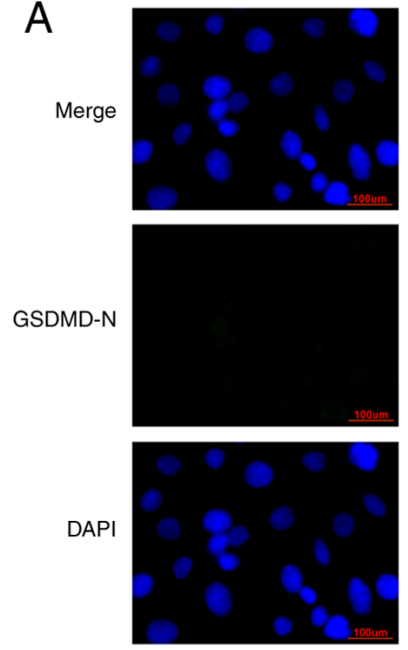

0
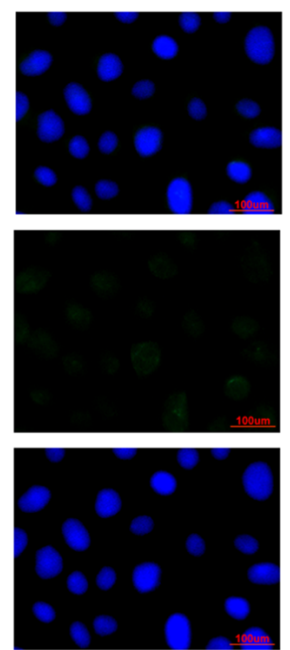

2
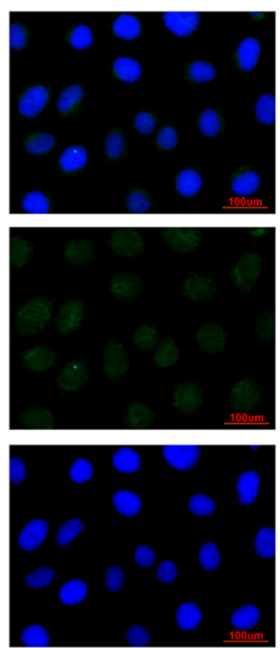

10
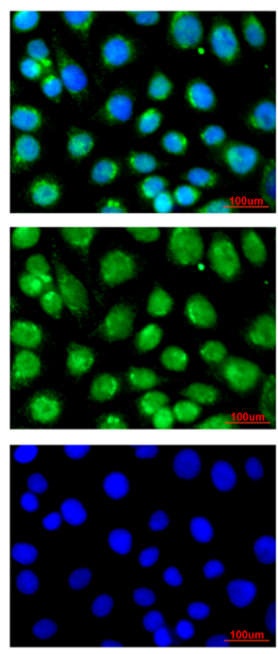

50
B

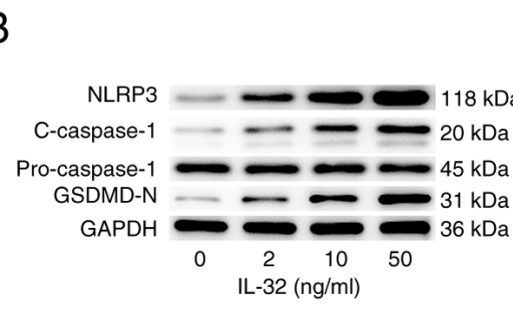

C

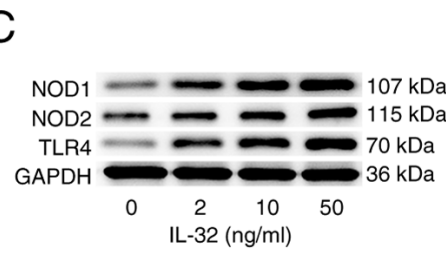

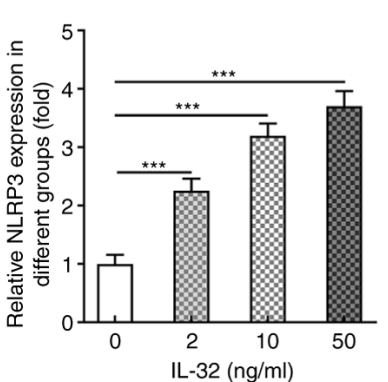

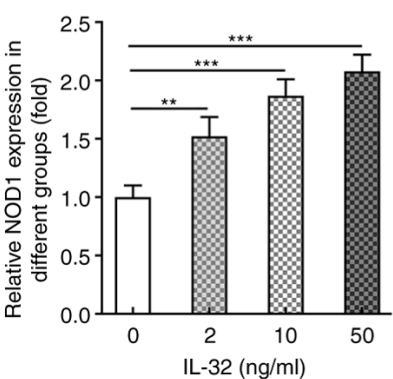

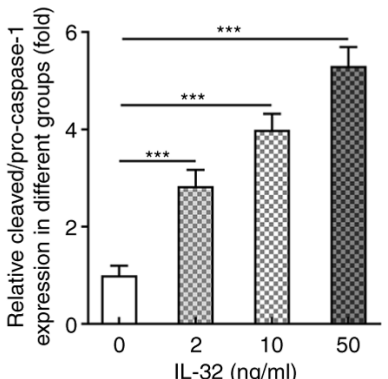
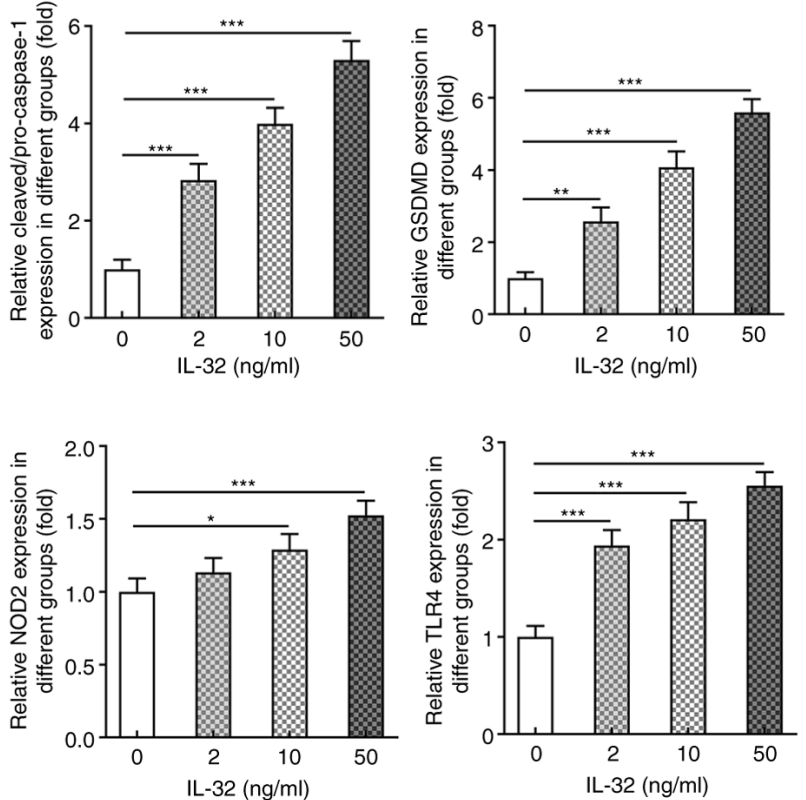

Figure 3. Effects of IL-32 on the expression of proteins involved in pyroptosis. (A) Representative immunofluorescence staining for GSDMD-N in HNEpCs exposed to 0, 2, 10 and $50 \mathrm{ng} / \mathrm{ml} \mathrm{IL-32} \mathrm{for} 48 \mathrm{~h}$. Scale bar, $100 \mu \mathrm{m}$. (B) The expression of NLRP3, cleaved-caspase-3/pro-caspase-3 and GSDMD-N in HNEpCs exposed to $0,2,10$ and $50 \mathrm{ng} / \mathrm{ml} \mathrm{IL-32} \mathrm{for} 48 \mathrm{~h}$ was detected via western blotting. (C) The expression of NOD1, NOD2 and TLR4 in HNEpCs exposed to 0,2, 10 and $50 \mathrm{ng} / \mathrm{ml} \mathrm{IL-32} \mathrm{for} 48 \mathrm{~h}$ was detected by western blotting. ${ }^{*} \mathrm{P}<0.05,{ }^{* * *} \mathrm{P}<0.01$ and ${ }^{* * * *} \mathrm{P}<0.001 \mathrm{vs.} 0 \mathrm{ng} / \mathrm{ml} \mathrm{IL}-32$. GSDMD-N, N-terminal of gasdermin $\mathrm{D}$; HNEpC, human nasal epithelial cell; NLRP3, NACHT LRR and PYD domains-containing protein 3; NOD, nucleotide-binding oligomerization domaincontaining protein; TLR, Toll-like receptor.

\section{Discussion}

The inflammatory response has been extensively reported to contribute to the occurrence and progression of $\mathrm{AH}(7,25)$. The present study aimed to analyze the association between the pro-inflammatory cytokine IL-32 and AH. IL-32 is a member of the IL family, which are lymphokines that interact between leukocytes or immune cells (13). To the best of our knowledge, the present study is the first to evaluate the association between IL-32 and AH. The results from the present study suggested the close association between IL-32 and AH pathogenesis as well as LPS-induced HNEpC injury.

Adenoids are considered to be essential parts of the system that protect organisms from pathogens. It is known that human adenoids are immunoreactive lymphoid organs, which exhibit specific antibodies together with $\mathrm{B}$ and $\mathrm{T}$ cell activities in response to various antigens performing the functions of humoral and cellular immunity (26). These are extremely important for the growth and development of children (26). At present, adenoidectomy is a direct and preferred method to solve AH in children, but it may bring risks and complications, including postoperative bleeding, nasopharyngeal stenosis and velopharyngeal insufficiency (27). Another possible risk is that removing adenoid tissue may result in a negative impact on immune function (28). These factors indicate the urgency to discover more suitable treatments.

ILs consist of a large family that can transmit information, activate and regulate immune cells, mediate the activation, 


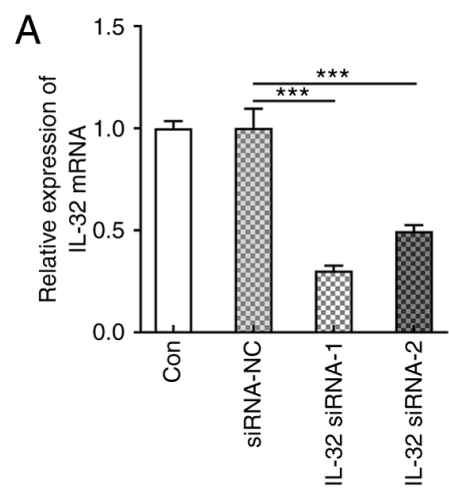

B
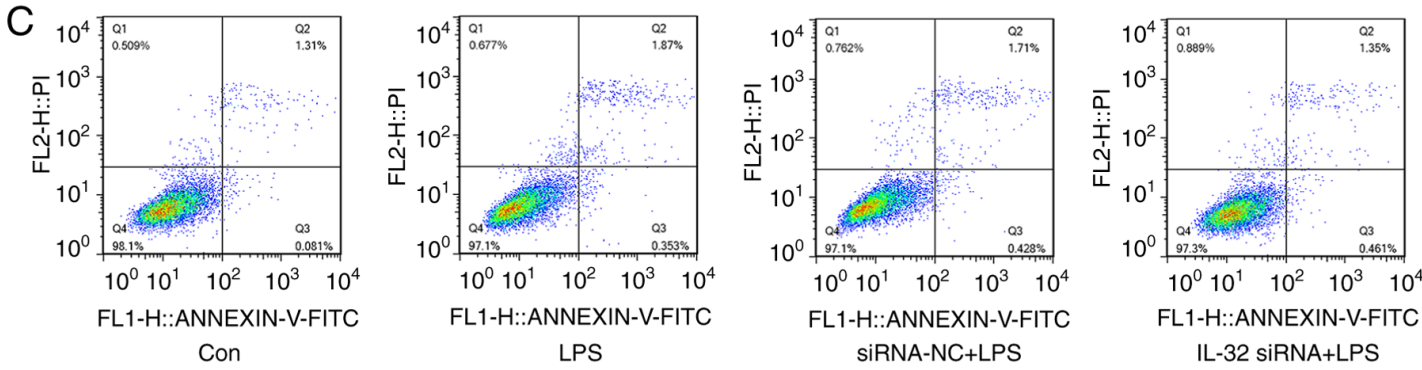

$\mathrm{E}$
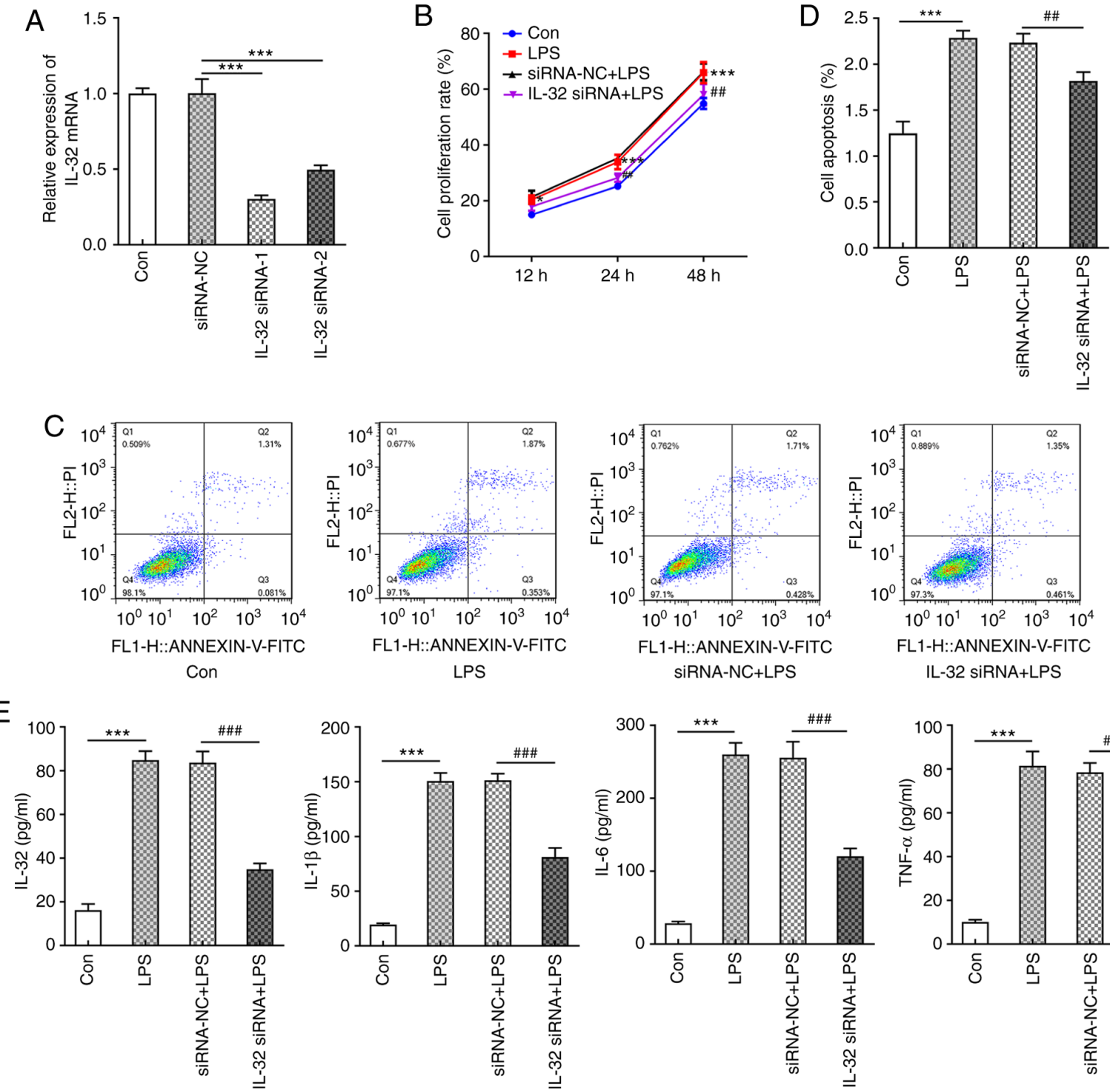

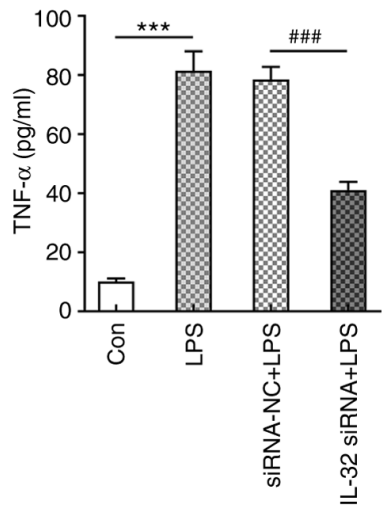

Figure 4. Effects of IL-32 silencing on LPS-induced HNEpC proliferation, apoptosis and inflammation. (A) The mRNA expression of IL-32 in control HNEpCs and HNEpCs transfected with corresponding siRNAs. ${ }^{* * *} \mathrm{P}<0.001$ vs. control. (B) The cell proliferation rate of control HNEpCs and HNEpCs transfected with corresponding siRNAs in the presence of LPS at 12,24 and $48 \mathrm{~h}$ post-treatment. ${ }^{*} \mathrm{P}<0.05$ and ${ }^{* * *} \mathrm{P}<0.001$, LPS vs. Control; ${ }^{\# \#} \mathrm{P}<0.001$, IL-32 siRNA + LPS vs. siRNA-NC + LPS. (C and D) The apoptotic ratio of control HNEpCs and HNEpCs transfected with corresponding siRNAs in the presence of LPS was detected by flow cytometry. (E) The concentration of TNF- $\alpha$, IL-6 and IL-1 $\beta$ in the culture medium of control HNEpCs and HNEpCs transfected with corresponding siRNAs in the presence of LPS was detected by ELISA. ${ }^{* * *} \mathrm{P}<0.001 \mathrm{vs}$. control; ${ }^{\# \#} \mathrm{P}<0.01$ and ${ }^{\# \# \#} \mathrm{P}<0.001$ vs. siRNA-NC + LPS. HNEpC, human nasal epithelial cells; LPS, lipopolysaccharide; siRNA, small interfering RNA; NC, negative control.

proliferation and differentiation of $\mathrm{T}$ and $\mathrm{B}$ cells and play an important role in inflammation. In addition to IL-32, numerous other IL members have also been illustrated to regulate airway inflammation (29-31). For example, IL-17A was found to be upregulated in adenoid tissues from patients with $\mathrm{AH}$ and pneumococcal carriage (32). IL-33 plays a role in the pathophysiology of chronic rhinosinusitis (30). These data indicate the modulatory role of ILs in AH and other types of airway inflammation. The present study found that IL-32, together with NLRP3 and IL-1 $\beta$, were significantly upregulated in AH tissues, indicating their role in AH. Subsequently, it was found that treatment with low concentrations of IL-32 (2 and $10 \mathrm{ng} / \mathrm{ml}$ ) could promote HNEpC proliferation, while higher concentrations of IL-32 $(50 \mathrm{ng} / \mathrm{ml})$ inhibited cell proliferation. This can be explained by the stressful cell proliferation caused by mild inflammation upon low concentrations of IL-32 (2 and
$10 \mathrm{ng} / \mathrm{ml}$ ) stimulation (24), but predominant apoptosis or cell death caused by high concentration of IL-32 $(50 \mathrm{ng} / \mathrm{ml})$ treatment. The present study showed that IL-32 significantly enhanced apoptosis, inflammation and the expression of proteins involved in pyroptosis in a concentration-dependent manner.

Pyroptosis is a newly discovered programmed cell death. It can cause excessive inflammation and immune response in tissues, which in turn results in local and even systemic inflammation and immunopathological damage (33). Pyroptosis can be divided into classical and non-classical pathways according to its recognition mechanisms, reactants and reaction pathways (16). Among both, GDSMD cleavage can expose its $\mathrm{N}$ domain with pore-forming activities, which forms a large pore in the membrane that induces pyroptosis (16). Meanwhile, the activation of inflammasome 
A
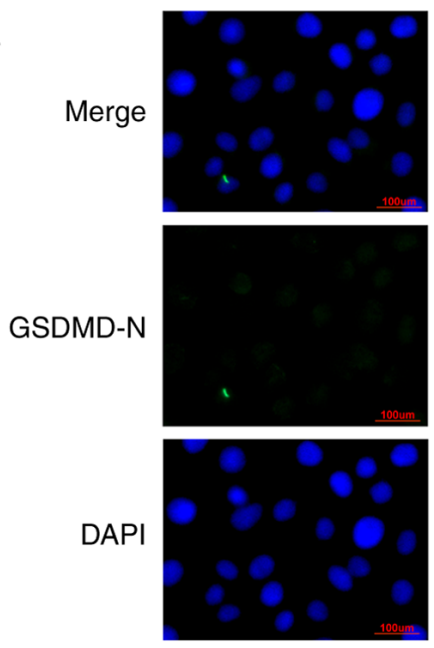

Con
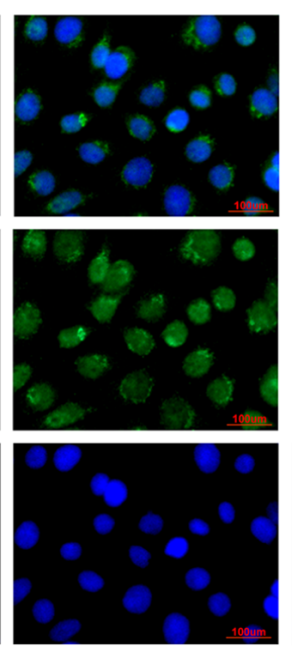

LPS
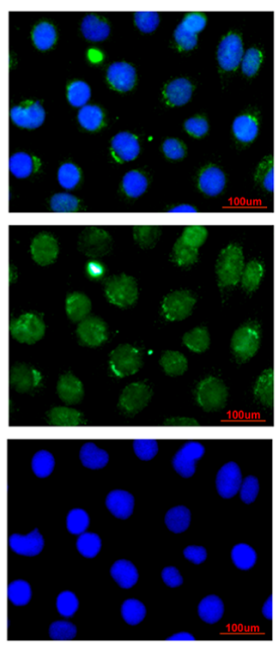

SiRNA-NC+LPS
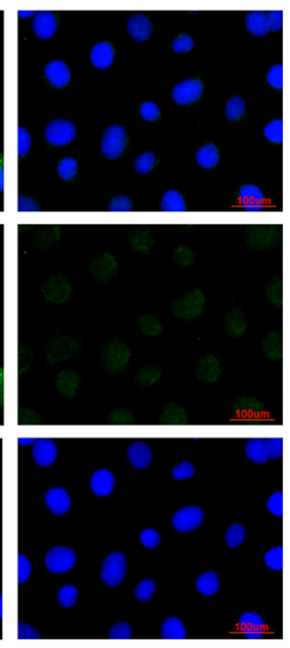

IL-32 siRNA+LPS

B
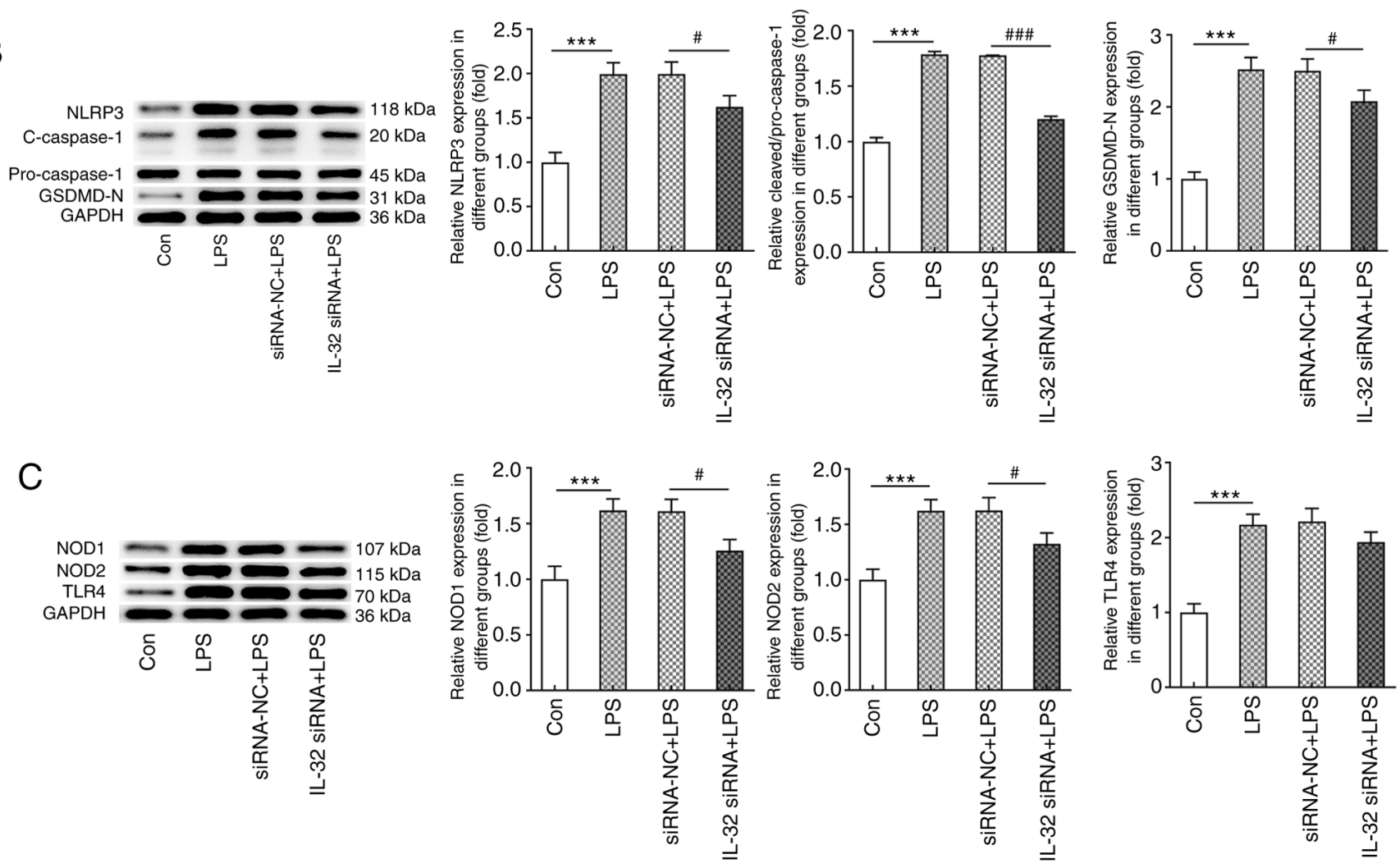

Figure 5. Effects of IL-32 silencing on LPS-induced HNEpC pyroptosis. (A) Immunofluorescence staining for GSDMD-N in control HNEpCs and HNEpCs transfected with corresponding siRNAs in the presence of LPS. Scale bar, $100 \mu \mathrm{m}$. (B) The expression of NLRP3, cleaved-caspase-3/pro-caspase-3 and GSDMD-N in control HNEpCs and HNEpCs transfected with corresponding siRNAs in the presence of LPS was detected by western blotting. (C) The expression of NOD1, NOD2 and TLR4 in control HNEpCs and HNEpCs transfected with corresponding siRNAs in the presence of LPS was detected by western blotting. ${ }^{* * *} \mathrm{P}<0.001$ vs. control; ${ }^{*} \mathrm{P}<0.05$ and ${ }^{\# \# \#} \mathrm{P}<0.001$ vs. siRNA-NC + LPS. HNEpC, human nasal epithelial cells; LPS, lipopolysaccharide; siRNA, small interfering RNA; NC, negative control; GSDMD-N, N-terminal of gasdermin D; NOD, nucleotide-binding oligomerization domain-containing protein; TLR, Toll-like receptor; NLRP3, NACHT LRR and PYD domains-containing protein 3.

NLRP3 induced by GSDMD-N and external stimuli can trigger caspase- 1 activation, thereby resulting in the release of a large number of pro-inflammatory cytokines, ultimately aggravating inflammation (17). The present results showed that IL-32 increased GSDMD-N, NLRP3 and cleavedcaspase-1 expression in HNEpCs, suggesting that IL-32 triggered pyroptosis in HNEpCs. TLRs and NOD-like receptors are two major pattern recognition receptors that provide responses against pathogenic invasion or tissue injury (34).
It has been reported that TLR4, NOD1 and NOD2 are also associated with airway inflammation (35). The present study found that IL-32 also promoted TLR4, NOD1 and NOD2 expression in a concentration-dependent manner. Notably, NOD1/2 and TLR4 are known to activate NF- $\mathrm{BB}$ signaling, which is able to trigger NLRP3 activation (36-37). Therefore, the present results indicated that IL-32 could also induce inflammation and NLRP3-mediated pyroptosis by activating pattern recognition receptors. 
To further verify the present hypothesis, IL-32 expression was silenced in HNEpCs stimulated with LPS using siRNA. Similar to IL-32, LPS significantly triggered high proliferation, apoptosis, inflammation and activation of GSDMD, NLRP3, caspase-1, NOD1/2 and TLR4. Besides, IL-32 knockdown significantly inhibited all effects induced by LPS, revealing the protective effects of IL-32 knockdown against LPS-induced injury in HNEpCs. To the best of our knowledge, the present study is the first to identify IL-32 as an important inflammatory cytokine involved in AH inflammation. However, this study were only carried out in a cell model, thus it lacks the validation of in vivo models. Future research will aim to verify these findings using in vivo experiments and uncover the specific underlying mechanisms involved in the actions of IL-32 in AH.

Taken together, the results of the present study demonstrated that during $\mathrm{AH}$ and upon LPS exposure, adenoid tissues and nasal epithelial cells released IL-32, which then regulated apoptosis and excretion of inflammatory cytokines via activation of the NOD1/2/TLR4/NLRP3 pathway, ultimately leading to pyroptosis. Approaches targeting IL-32 to downregulate its expression may provide novel therapeutic targets for $\mathrm{AH}$. However, further in vivo and clinical investigations need to be performed.

\section{Acknowledgements}

Not applicable.

\section{Funding}

No funding was received.

\section{Availability of data and materials}

The datasets used and/or analysed during the current study are available from the corresponding author on reasonable request.

\section{Authors' contributions}

JZ and XS conceived and designed the study. JZ, XS, LZ and BS acquired and analyzed the data. JZ and XS confirmed the authenticity of all the raw data. JZ prepared the draft of the manuscript, including the figures. All authors read and approved the final manuscript.

\section{Ethics approval and consent to participate}

All experimental procedures were approved by the Ethical Committee of the Tianjin Children's Hospital (Tianjin, China). The parents of the children were informed about the study and consent was obtained.

\section{Patient consent for publication}

Not applicable.

\section{Competing interests}

The authors declare they have no competing interests.

\section{References}

1. Coca-Pelaz A, Rodrigo JP, Bradley PJ, Vander Poorten V, Triantafyllou A, Hunt JL, Strojan P, Rinaldo A, Haigentz M Jr, Takes RP, et al: Adenoid cystic carcinoma of the head and neck - An update. Oral Oncol 51: 652-661, 2015.

2. Buzatto GP, Tamashiro E, Proenca-Modena JL, Saturn TH, Prates MC, Gagliardi TB, Carenzi LR, Massuda ET, Hyppolito MA, Valera FC, et al: The pathogens profile in children with otitis media with effusion and adenoid hypertrophy. PLoS One 12: e0171049, 2017.

3. Durgut O and Dikici O: The effect of adenoid hypertrophy on hearing thresholds in children with otitis media with effusion. Int J Pediatr Otorhinolaryngol 124: 116-119, 2019.

4. Stupak HD and Park SY: Gravitational forces, negative pressure and facial structure in the genesis of airway dysfunction during sleep: A review of the paradigm. Sleep Med 51: 125-132, 2018.

5. Scadding G: Non-surgical treatment of adenoidal hypertrophy: the role of treating IgE-mediated inflammation. Pediatr Allergy Immunol 21: 1095-1106, 2010.

6. Gulotta G, Iannella G, Vicini C, Polimeni A, Greco A, de Vincentiis M, Visconti IC, Meccariello G, Cammaroto G, De Vito A, et al: Risk factors for obstructive sleep apnea syndrome in children: Int J Environ Res Public Health 16: 3235,2019.

7. Marazzato M, Zicari AM, Aleandri M, Conte AL, Longhi C, Vitanza L, Bolognino V, Zagaglia C, De Castro G, Brindisi G, et al: 16S metagenomics reveals dysbiosis of nasal core microbiota in children with chronic nasal inflammation: Role of adenoid hypertrophy and allergic rhinitis. Front Cell Infect Microbiol 10: 458, 2020.

8. Hong JT, Son DJ, Lee CK, Yoon DY, Lee DH and Park MH: Interleukin 32, inflammation and cancer. Pharmacol Ther 174: 127-137, 2017.

9. Jeong HJ, Shin SY, Oh HA, Kim MH, Cho JS and Kim HM: IL-32 up-regulation is associated with inflammatory cytokine production in allergic rhinitis. J Pathol 224: 553-563, 2011.

10. Nam SY, Oh HA, Choi Y, Park KY, Kim HM and Jeong HJ: Inhibition of IL-32 signaling by bamboo salt decreases proinflammatory responses in cellular models of allergic rhinitis. J Med Food 17: 939-948, 2014.

11. Jeong HJ, Oh HA, Lee BJ and Kim HM: Inhibition of IL-32 and TSLP production through the attenuation of caspase-1 activation in an animal model of allergic rhinitis by Naju Jjok (Polygonum tinctorium). Int J Mol Med 33: 142-150, 2014.

12. Keswani A, Kern RC, Schleimer RP and Kato A: Role of interleukin-32 in chronic rhinosinusitis. Curr Opin Allergy Clin Immunol 13: 13-18, 2013.

13. Kim SH, Han SY, Azam T, Yoon DY and Dinarello CA: Interleukin-32: A cytokine and inducer of TNFalpha. Immunity 22: 131-142, 2005.

14. Pan X, Cao H, Lu J, Shu X, Xiong X, Hong X, Xu Q, Zhu H, Li G and Shen G: Interleukin-32 expression induced by hepatitis $\mathrm{B}$ virus protein $\mathrm{X}$ is mediated through activation of NF- $\kappa \mathrm{B}$. Mol Immunol 48: 1573-1577, 2011.

15. Lu J, Fang K, Wang S, Xiong L, Zhang C, Liu Z, Guan X, Zheng R, Wang G, Zheng J, et al: Anti-inflammatory effect of columbianetin on lipopolysaccharide-stimulated human peripheral blood mononuclear cells. Mediators Inflamm 2018: 9191743, 2018.

16. Wang S, Yuan YH, Chen NH and Wang HB: The mechanisms of NLRP3 inflammasome/pyroptosis activation and their role in Parkinson's disease. Int Immunopharmacol 67: 458-464, 2019.

17. Yang Z, Liang C, Wang T, Zou Q, Zhou M, Cheng Y, Peng H, Ji Z, Deng Y, Liao J, et al: NLRP3 inflammasome activation promotes the development of allergic rhinitis via epithelium pyroptosis. Biochem Biophys Res Commun 522: 61-67, 2020.

18. Hu H and Li H: Prunetin inhibits lipopolysaccharide-induced inflammatory cytokine production and MUC5AC expression by inactivating the TLR4/MyD88 pathway in human nasal epithelial cells. Biomed Pharmacother 106: 1469-1477, 2018.

19. Tsou YA, Tung YT, Wu TF, Chang GRL, Chen HC, Lin CD, Lai $\mathrm{CH}$, Chen HL and Chen CM: Lactoferrin interacts with SPLUNC1 to attenuate lipopolysaccharide-induced inflammation of human nasal epithelial cells via down-regulated MEK1/2-MAPK signaling. Biochem Cell Biol 95: 394-399, 2017.

20. Li YQ, Zhong Y, Xiao XP, Li DD, Zhou Z and Tian YY: IL-33/ ST2 axis promotes the inflammatory response of nasal mucosal epithelial cells through inducing the ERK1/2 pathway. Innate Immun 26: 505-513, 2020. 
21. Nian JB, Zeng M, Zheng J, Zeng LY, Fu Z, Huang QJ and Wei X Epithelial cells expressed IL-33 to promote degranulation of mast cells through inhibition on ST2/PI3K/mTOR-mediated autophagy in allergic rhinitis. Cell Cycle 19: 1132-1142, 2020.

22. Lin J, Xu R, Hu L, You J, Jiang N, Li C, Che C, Wang Q, Xu Q, Li J, et al: Interleukin-32 induced thymic stromal lymphopoietin plays a critical role in the inflammatory response in human corneal epithelium. Cell Signal 49: 39-45, 2018.

23. Livak KJ and Schmittgen TD: Analysis of relative gene expression data using real-time quantitative PCR and the 2(-Delta Delta C(T)) Method. Methods 25: 402-408, 2001.

24. Kiraly O, Gong G, Olipitz W, Muthupalani S and Engelward BP: Inflammation-induced cell proliferation potentiates DNA damage-induced mutations in vivo. PLoS Genet 11: e1004901, 2015.

25. Anfuso A, Ramadan H, Terrell A, Demirdag Y, Walton C, Skoner DP and Piedimonte G: Sinus and adenoid inflammation in children with chronic rhinosinusitis and asthma. Ann Allergy Asthma Immunol 114: 103-110, 2015.

26. Sun YL, Zheng HT, Tao JL, Jiang MC, Hu CC, Li XM and Yuan B: Effectiveness and safety of Chinese herbal medicine for pediatric adenoid hypertrophy: A meta-analysis. Int J Pediatr Otorhinolaryngol 119: 79-85, 2019.

27. Richter GT and Bower CM: Cervical complications following routine tonsillectomy and adenoidectomy. Curr Opin Otolaryngol Head Neck Surg 14: 375-380, 2006.

28. van den Akker EH, Sanders EA, van Staaij BK, Rijkers GT, Rovers MM, Hoes AW and Schilder AG: Long-term effects of pediatric adenotonsillectomy on serum immunoglobulin levels: Results of a randomized controlled trial. Ann Allergy Asthma Immunol 97: 251-256, 2006.

29. Rogala B and Glück J: The role of interleukin-33 in rhinitis. Curr Allergy Asthma Rep 13: 196-202, 2013.

30. Kim DK, Jin HR, Eun KM, Mo JH, Cho SH, Oh S, Cho D and Kim DW: The role of interleukin-33 in chronic rhinosinusitis. Thorax 72: 635-645, 2017.
31. Luo XQ, Ma F, Wang S, Zhao MZ, Shao JB, Geng XR, Liu JQ, Mo LH, Guan L, Liu ZG, et al: Interleukin-5 induces apoptotic defects in $\mathrm{CD}^{+} \mathrm{T}$ cells of patients with allergic rhinitis. J Leukoc Biol 105: 719-727, 2019.

32. Huang CC, Wu PW, Chen CL, Wang CH, Lee TJ, Tsai CN and Chiu CH: IL-17A expression in the adenoid tissue from children with sleep disordered breathing and its association with pneumococcal carriage. Sci Rep 8: 16770, 2018.

33. Bergsbaken T, Fink SL and Cookson BT: Pyroptosis: Host cell death and inflammation. Nat Rev Microbiol 7: 99-109, 2009.

34. Keestra-Gounder AM, Byndloss MX, Seyffert N, Young BM, Chávez-Arroyo A, Tsai AY, Cevallos SA, Winter MG, Pham OH, Tiffany CR, et al: NOD1 and NOD2 signalling links ER stress with inflammation. Nature 532: 394-397, 2016.

35. Di Stefano A, Ricciardolo FLM, Caramori G, Adcock IM, Chung KF, Barnes PJ, Brun P, Leonardi A, Andò F, Vallese $\mathrm{D}$, et al: Bronchial inflammation and bacterial load in stable COPD is associated with TLR4 overexpression. Eur Respir J 49: 1602006, 2017.

36. Luo M, Yan D, Sun Q, Tao J, Xu L, Sun H and Zhao H Ginsenoside Rg1 attenuates cardiomyocyte apoptosis and inflammation via the TLR4/NF- $\mathrm{BB} / \mathrm{NLRP} 3$ pathway. J Cell Biochem 121: 2994-3004, 2020

37. Aabdin ZU, Bilal MS, Dai H, Abaker JA, Liu X, Benazir S, Yan J and Shen X: NOD1/NF- $\mathrm{B}$ B signaling pathway inhibited by sodium butyrate in the mammary gland of lactating goats during sub-acute ruminal acidosis. Microb Pathog 122: 58-62, 2018.

This work is licensed under a Creative Commons Attribution-NonCommercial-NoDerivatives 4.0 International (CC BY-NC-ND 4.0) License. 